\title{
A Cultural Awakening: The Harlem Renaissance revisited
}

Due to the lack of diversity at the University of Vermont (UV) and its community, I wanted to broaden experiences by bringing a sampling of the African American experience via the Harlem Renaissance to these communities.

I wrote, received, and administered a grant in the spring of 1998 to develop a three-credit course, "The Harlem Renaissance Revisited." The course, offered through the Division of Continuing Education, was augmented by a number of university-wide events:

January 15-March 15, 1998, "The Legacy of Arthur Schomburg," a traveling display, was

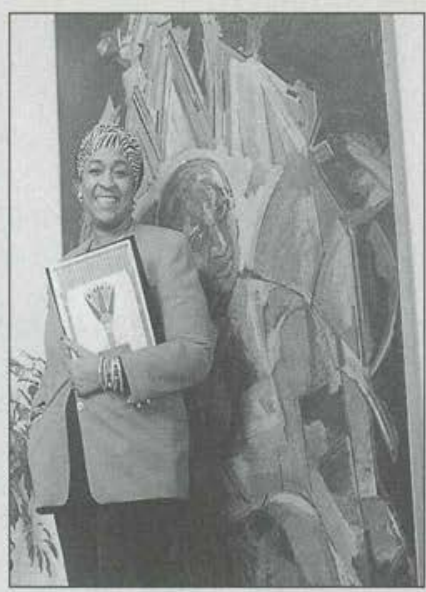

Marilyn Nelson, seen here with the University of Vermont's Bailey/ Howe Library's (McCrorey Gallery) signature painting, the 1975 "Portrait of the Black Man," by Instructional Incentive grant from the provost and organized, administered, developed, and taught "The Harlem Renaissance Revisited." Milton Derr. Nelson netted an

"From These Roots," "Two Dollars and a 츰 Dream," "Black Artist of the USA," and "Harlem Renaissance and $\mathrm{Be}$ yond."

In March, "Two Cregave Women in the Har¿ lem Renaissance Ethos: The 1920s Anne Spencer and the 1990s Dolores Sandoval," was introduced with a brief biography on Spencer. The 1920 s iconoclast was a writer and librarian whose Lynchburg, Virginia, home became a haven for many of the 1920 s black intelligentsia. Sadly, two legendary librarians, Augusta Baker and Jean Blackwell Hutson, died in February as their contributions to hung in the Bailey/Howe Library's H. Lawrence McCrorey Gallery of Multicultural Art at UV. Schomburg's collections of the black experience in books, manuscripts, and art form the core of the New York Public Library's Schomburg Center for Research in Black Culture. Professor Mary Jane Dickerson opened our "Spring Calendar of Events" with a discussion of Ann Douglas's Terrible Honesty: Mongrel New York in the 1920s.

February offered a compelling lecture and slide presentation, "The Face and Heart of the Black Renaissance," by Edmund Barry Gaither, director of the Museum of the National Center of Afro-American Artists in Boston, and "Aspects of the Harlem Renaissance," a faculty panel and open discussion led by UV's Professor Donald Grinde with professors from Dartmouth, Middlebury, and Bennington colleges. UV alumnus William O. Boyd, who as a boy worked for Langston Hughes, was our special guest. Bailey/ Howe's February Film Festival included the Schomburg hung in the Bailey/Howe Library.

Our closing speaker, Linda Perkins, Hunter College, lectured from her newly published essay, "The African American Female Elite: The Early History of African American Women in the Seven Sister Colleges, 1880 1960." The finale in April featured "Music of the Harlem Renaissance," by Larry McCrorey's "Just Jazz." The mixtures of sights, sounds, and colors at each event recalled the ambience of a Harlem Renaissance soiree.

The reawakening was deemed a success and best summed up by a staff member who said, "I was unaware of the Harlem Renaissance, except for the music of Duke Ellington. During this cultural awakening I became aware of Black American history, art, and literature." My objective exactly!Marilyn Nelson, library assistant professor, Bailey/Howe Library, University of Vermont, e-mail:mxnelson@zoo.uvm.edu. 